\title{
Prevalence of teenage pregnancy and pregnancy outcome at a rural teaching hospital in India
}

\author{
Okram Sarda Devi, Ke Manga Reddy, \\ B. Sree Chaitanya Naga Samyukta, P. Sadvika, Kalpana Betha*
}

Department of Obstetrics and Gynecology, Mediciti Institute of Medical Sciences, Medchal, Hyderabad, Telangana, India

Received: 02 December 2018

Accepted: 29 December 2018

*Correspondence:

Dr. Kalpana Betha,

E-mail: kalpanabasany@gmail.com

Copyright: () the author(s), publisher and licensee Medip Academy. This is an open-access article distributed under the terms of the Creative Commons Attribution Non-Commercial License, which permits unrestricted non-commercial use, distribution, and reproduction in any medium, provided the original work is properly cited.

\section{ABSTRACT}

Background: Teenage pregnancy accounts for $11 \%$ of births worldwide and $95 \%$ of these occur in low middle income countries. Pregnancy and its complications are leading cause of death among these girls. This study was done to know the prevalence and to determine whether teenage mothers are at risk of adverse pregnancy outcome.

Methods: A retrospective study was conducted at a tertiary teaching hospital, India between July 2015 to Dec, 2017. All teenage mothers delivered after 28 weeks of gestation were included. Women with Diabetes mellitus, renal disease, thyroid disorders were excluded. Demographic data, maternal complications like anaemia, hypertensive disorders of pregnancy, preterm birth, mode of delivery, low birth weight, NICU admissions, stillbirth and early neonatal death were recorded.

Results: In the present study, the prevalence was $7 \%$ which is less than that of other studies. Incidence of caesareanSection in the present study was $31 \%$. Amongst the complications oligohydramnious was found to be significantly associated with teenage pregnancy. NICU admissions were needed for $43 \%$ of the cases and $31 \%$ were LBW.

Conclusions: High NICU admission and high LBW in newborns of teenage mothers were noted in the current study. Hence, there is urgent need to focus on the teenage pregnancy.

Keywords: LBW, NICU, Oligohydramnios, Teenage pregnancy

\section{INTRODUCTION}

According to World Health Organization, Teenage Pregnancy is "any pregnancy from a girl who is 10-19 years of age", the age being defined as her age at the time the baby is born. ${ }^{1,2}$ Teenage pregnancy is very important health as well social issue in today's world. Teenage pregnancy accounts for $11 \%$ of births worldwide. According to UNICEF, worldwide every 5 th child is born to teenage mother. ${ }^{3} 90 \%$ occur in low middle income countries. ${ }^{4}$ Unlike developed countries where majority of teenage pregnancy occurs in unmarried girls, in India majority of teenage pregnancies are because of teenage marriages. Even though adolescent marriage is cognizable offence in India, it is still a common practice in many parts of the country. Pregnancy and its complications are leading cause of death among these girls. ${ }^{3}$ Teenage pregnancies have shown associations with preterm birth, low birth weight, perinatal death, miscarriage, obstructed labour, STI, puerperal sepsis, mental illness and maternal death. However, the evidence is conflicting and may be explained by the heterogeneity of the study settings, sample sizes. ${ }^{5-8}$ Hence, there is a need for the studies, especially from low income countries where most of the adverse obstetric outcomes happen. So, we aim to determine whether these pregnancies are associated with adverse maternal and 
perinatal outcome compared to mothers more than $20 \mathrm{yrs}$ at a rural tertiary teaching hospital, India.

\section{METHODS}

This is a retrospective observational study conducted at Mediciti Institute of Medical Sciences, a rural tertiary teaching hospital located $35 \mathrm{~km}$ from the city of Hyderabad in Telangana state, India. All pregnancy cases less than 19 years of age constituted the study group and women between 20 to 35 years of age formed the control group.

All deliveries in the hospital and pregnancy outcomes are reviewed. Using each woman's unique medical record number, case files were obtained, and data were obtained on demographic variables and associated complications such as anaemia, hypertensive disorders of pregnancy, preterm birth, polyhydramnios etc. Data regarding mode of delivery, gestational age at delivery, weight of the baby, NICU admission, still birth, IUD were recorded. Gestational age was obtained by last menstrual period and confirmed by dating scan. First trimester dating ultrasound was used where date of last menstrual period was not known. Pre-eclampsia is defined as hypertension at $>20$ weeks of pregnancy, combined with proteinuria. ${ }^{9}$ Gestational hypertension is defined by an elevated BP at or beyond 20 weeks of gestation in the absence of proteinuria. ${ }^{10}$ Polyhydramnios is defined as Amniotic fluid index $>24 \mathrm{~cm}$. ${ }^{11}$ Amniotic fluid index (AFI) of $<5$ is defined as oligohydramnios. Preterm delivery is defined as spontaneous or iatrogenic delivery before gestational week 37. ${ }^{12,13}$ Low birth weight (LBW) is defined as weight less than 2500 grams at birth regardless of gestational age. ${ }^{14}$ Anaemia during pregnancy is defined as hemoglobin $(\mathrm{Hb})$ concentration less than $11 \mathrm{~g} / \mathrm{dL} .{ }^{15}$ Gestational diabetes mellitus (GDM) is defined as any degree of glucose intolerance with the onset or first recognition during pregnancy with or without remission after the end of pregnancy. ${ }^{16}$

\section{RESULTS}

Out of 4837 deliveries that occurred at MIMS from July 2015 to Dec 2017, 356 deliveries occurred were teenage mothers giving the prevalence rate of $7 \%$.

Table 1: Demographic profile of the teenage mothers.

\begin{tabular}{|l|l|l|l|l|l|}
\hline Parameters (Gravidity) & Case (\%) & Control (\%) & Odds Ratio & C.I & P Value \\
\hline Primi & $306(86 \%)$ & $129(36 \%)$ & 10.5 & $7.29-15.1$ & 0.0001 \\
\hline Multi & $51(14 \%)$ & $227(64 \%)$ & 0.09 & $0.06-0.13$ & 0.0001 \\
\hline Parameters (Religion) & & & & \\
\hline Hindu & $334(94 \%)$ & $337(95 \%)$ & & \\
\hline Muslim & $20(5.5 \%)$ & $19(5 \%)$ & & \\
\hline Christian & $2(0.5 \%)$ & $0(0 \%)$ & & & \\
\hline Booked/ Unbooked & & & & \\
\hline Booked & $340(96 \%)$ & $326(92 \%)$ & & \\
\hline Unbooked & $16(4 \%)$ & $30(8 \%)$ & & \\
\hline
\end{tabular}

Table 2: Distribution of complications seen with teenage pregnancies and the control group.

\begin{tabular}{|l|l|l|l|l|l|}
\hline Complications & Case $(\%)$ & Control $(\%)$ & Odds Ratio & C.I & P Value \\
\hline Anaemia & $155(44 \%)$ & $154(43 \%)$ & 1.01 & $0.75-1.36$ & 0.93 \\
\hline PIH & $31(9 \%)$ & $30(8 \%)$ & 1.03 & $0.61-1.75$ & 0.89 \\
\hline Oligohydramnios & $27(8 \%)$ & $9(3 \%)$ & 3.1 & $1.46-6.82$ & 0.003 \\
\hline Preterm delivery & $32(8 \%)$ & $19(5 \%)$ & 1.75 & $0.97-3.15$ & 0.061 \\
\hline GDM & $5(0.01 \%)$ & $4(0.01 \%)$ & 0.49 & $0.09-2.73$ & 0.4 \\
\hline
\end{tabular}

There were $306(86 \%)$ primigravidas and 51(14\%) multigravidas in the study group, while 129(36\%) were primigravidas and $227(64 \%)$ were multigravidas in the control group. The proportion of primigravidas were high in the teenage women $(\mathrm{OR}=10.5,95 \% \mathrm{CI}$ 7.29-15.1. P $<0.0001)$. Most of the women in both the groups belonged to low socio-economic status (Table 1). Most women $(96 \%$ in the study group and $92 \%$ in the control group) has registered themselves at our institute and had regular ANC visits. Most of the women were Hindus
(94\% and $95 \%$ respectively). The prevalence rate of teenage pregnancy was $7 \%$. Only $14 \%$ were multigravida. Most of the patients were Hindus (94\%) and were booked cases (96\%). Anaemia was the most common complications seen in the teenage women (44\%) but was not different from the control group (43\%) (Table 2). Oligohydramnios was seen in $8 \%$ of teenage women and only in $3 \%$ of the control group and was found to be significant (OR 3.1,CI1.466.82,P0.003).GDM accounted for only $0.01 \%$ of the cases 
in both the groups. Majority of the women in both the groups delivered vaginally $(59.5 \%$ vs $42.1 \%$; OR $1.85,95 \%$ CI-1.35-2.48,P=0.0001). Instrumental vaginal delivery was $8.9 \%$ and $5.3 \%$ respectively and there was no statistically significant difference (Table 3). Caesarean section were $31.4 \%$ and $50.2 \%$ respectively in the study and control group and was found to be statistically significant $(\mathrm{P}=0.0001)$. The incidence of $\mathrm{LBW}$ in teenage women and control group was $31 \%$ and $26 \%$ respectively. However, it was not statistically significant $\mathrm{P}=0.08 \%$. NICU admission was required in $43 \%$ and $34 \%$ of the babies in the study and control groups respectively (Table 4).

Table 3: Mode of delivery in both the groups.

\begin{tabular}{|l|l|l|l|l|l|}
\hline Mode of Delivery & Case (\%) & Control (\%) & Odds ratio & C.I & \multicolumn{1}{c|}{ P Value } \\
\hline Normal vaginal delivery & $212(59.5 \%)$ & $158(42.1 \%)$ & 1.85 & $1.38-2.48$ & 0.0001 \\
\hline Instrumental (forceps + vacuum) delivery & $32(8.9 \%)$ & $19(5.3 \%)$ & 1.75 & $0.97-8.15$ & 0.061 \\
\hline LSCS & $112(31 \%)$ & $179(50 \%)$ & 0.33 & $0.33-0.61$ & 0.0001 \\
\hline
\end{tabular}

Table 4: Neonatal outcome in both the groups.

\begin{tabular}{|l|l|l|l|l|l|}
\hline Neonatal complications & Case $(\%)$ & Control $(\%)$ & Odds Ratio & C.I & P Value \\
\hline NICU & $154(43 \%)$ & $122(34 \%)$ & 1.46 & $1.07-1.98$ & 0.01 \\
\hline LBW & $112(31 \%)$ & $91(26 \%)$ & 1.33 & $0.96-1.85$ & 0.08 \\
\hline IUD & $6(02 \%)$ & $5(02 \%)$ & 1.2 & $0.36-3.9$ & 0.76 \\
\hline
\end{tabular}

\section{DISCUSSION}

According to the National Health Survey -4, Telangana has the second highest number of teenage pregnancy cases in south India. In rural areas, the number of teenage pregnancy cases was $13.8 \%$ as opposed to $6.6 \%$ in urban areas. ${ }^{17}$ The prevalence of teenage pregnancy in our study was $7 \%$ which was par with the numbers quoted by NHFS - data. This may be explained by the fact that this area is slowly transforming into peri urban area. Still low rates of teenage pregnancies were quoted by Gazala Yasmin et al study 5.1\% and Dubashi et al(4.5\%). ${ }^{18,19}$ Teenage pregnancy, where the maternal age is 19 years or less is associated with health risk for both mother and the fetus which are sometimes life threatening. The current study is a retrospective study from July 2015 to Dec 2017.A total of 356 teenage pregnancies were included in the study. Over the past decade, India has significantly reduced the portion of pregnancies between 15-19 years to half $16 \%$ during NFHS3 in 2005-06 and 7.9\% during NFHS -4 in 2015-16). ${ }^{17}$ Most of the women were primigravidas in the teenage group $(86 \%)$ which is in consistent with the study by Mahavarkar et al where $86.85 \%$ of teenage women were primigravidas. ${ }^{20}$ In the current study, the proportion of women who booked for antenatal care was very high $(96 \%)$ as all women are married and childbearing is often accepted socially, and pregnancies were planned. Also, easy access to medical facility at hospital also contributed to high rates of booking. On the contrary, most high-income countries have low teenage pregnancy rates and majority of the pregnancies are amongst unmarried teenagers. Teenage pregnancy carries high risk to both mother and infant. Anaemia was the most common complication seen in the current study. Generally, the cause of anaemia is not the young age of the adolescent mother. It is often caused by the nutritional deficiencies, especially iron and folic acid, and in low income countries by malaria and hookworm infection. In a study by Mahavarkar et al, anaemia was also the most common complication seen. ${ }^{20}$ The second most common complication seen was PIH (9\%) as the number of nulliparious women were much higher and because in first pregnancies, the incidence of hypertension disorders is higher than second pregnancies. A slightly high rate of PIH was reported in Mahavarkar study. ${ }^{20}$ However in the global Network Maternal Newborn Health Registry Study, compared to adult, adolescents $<15$ years showed a statically significant lower risk of hypertensive disorders(RR0.32.95\% CI0.12$0.86)^{21}$

There was statistically significant difference in the incidence of oligohydramnios in the adolescent group compared to the control group in the current study $(\mathrm{P}=0.003)$. However, this condition could not be compared as this complication was not studied in other studies. A good number of studies both populations based and hospital-based studies from many countries published till date, comparing the risk of preterm in teenage verses adult pregnant women. Most of the studies found more preterm births in adolescents and made it clear that maternal age is an important independent factor. Our rate of preterm $(8 \%)$ was almost in agreement with Althabe et al study. ${ }^{21}$ The caesarean rate was higher at $31 \%$ in the present study. This can be explained by the fact that pelvic bones and the birth canal are still immature and may cause obstructed labour.] Mukhopadhyay et al also quoted a higher rate $(34 \%){ }^{22} \mathrm{LBW}$ rate was high in the current study (31\%).A number of hospital-based studies in developing countries have shown higher incidence of 
LBW babies among adolescent mothers (Bacci et al LBW will be closely associated with preterm birth. ${ }^{23}$ NICU admission were also high in the study group (43\%) as LBW were high in this group.

\section{CONCLUSION}

Teenage pregnancy with prevalence of $7 \%$ is still a major problem in our Indian society. Knowing the facts that teenage pregnancy is associated with major complications of pregnancy both maternal and neonatal, there is urgent need to focus and decrease the teenage pregnancy in our society.

\section{Funding: No funding sources}

Conflict of interest: None declared

Ethical approval: The study was approved by the Institutional Ethics Committee

\section{REFERENCES}

1. World Health Organization, United Nations Population Fund: Married adolescents: no place of safety. Geneva: WHO-UNFPA;2006.

2. Adolescent pregnancy- Issues in adolescent health and development, WHO discussion papers on adolescence. WHO, 2004;86.

3. UNICEF. A league table of teenage births in rich nations: Innocenti Report Card No. 3: The United Nations Children's Fund. Florence, Italy: Innocenti Research Centre. 2001.

4. Tunick B. Risks and realities of early childbearing worldwide. Alan Guttmacher Institute Washington, D.C., Alan Guttmacher Institute [AGI], 1996 Dec. 8 p.

5. Suwal A. Obstetric and Perinatal Outcome of Teenage Pregnancy. J Nepal Health Res Counc. 2012;10(20):52-6.

6. Hammad SM, Al-Enazi RQ. Does teenage pregnancy affect obstetric outcomes? Egypt J Comm Med.2010;26(3):25-35.

7. Pun KD, Chauhan M. Outcomes of Adolescent Pregnancy at Kathmandu University Hospital, Dhulikhel Hospital. Kathmandu Univ Med J 2011;33(1):50-3.

8. Supanan Chairaj, Kasorn Tosang, Suvanna Asavapiriyanont, Uraiwan Chotigeat. Outcome of Teenage Pregnancy in Rajavithi Hospital. J Med Assoc Thai 2010;93(1):1-8.

9. English FA, Kenny LC, McCarthy FP. Risk factors and effective management of preeclampsia. Integr Blood Press Cont. 2015;8:7-12.

10. Report of the National High Blood Pressure Education Program Working Group on High Blood Pressure in Pregnancy. Am J Obstet Gynecol. 2000; 183(1):S1-22.

11. Cunningham FG, Leveno KJ, Bloom SL, Hauth JC, Rouse DJ, Spong CY. Pregnancy Hypertension. In:
Cunningham, F.G., Leveno, K.J., Bloom, S.L., Hauth, J.C., Rouse, D.J. and Spong, C.Y., Eds., Williams Obstetrics, 23 ${ }^{\text {rd }}$ Edition, 2010, McGrawHill, New York,706-756.

12. Phelan JP, Smith CV, Small M. Amniotic fluid volume assessment with four quadrant technique at 36-42 weeks of gestation. J Repod Med 1987;32(7):540-2.

13. Pennell CE, Jacobsson B, Williams SM, Buus RM, Muglia LJ, Dolan SM, et al. Genetic epidemiologic studies of preterm birth: guidelines for research. Am J Obstet Gynecol 2007;196(2):107-18.

14. Kramer MS. Determinants of LBW, Methodological assessment and meta-analysis. WHO Bull. 1987; 65(5):663-737.

15. World Health Organization (WHO), Hemoglobin Concentrations for the Diagnosis of Anaemia and Assessment of Severity, Vitamin and Mineral Nutrition Information System, World Health Organization (WHO), Geneva, Switzerland, 2011.

16. Seshiah V, Das AK, Balaji V, Joshi SR, Parikh MN, Gupta S. Diabetes in Pregnancy Study Group. Gestational diabetes mellitus-guidelines. J Assoc Physicians India. 2006;54:622-8.

17. National Family Health Survey:4 State Fact Sheet Telangana Available at http://rchiips.org/NFHS/pdf/NFHS4/TG_FactSheet.p df

18. Gazala Yasmin, Aruna Kumar, Bharti Parihar. Teenage Pregnancy:Its Impact on maternal and fetal outcome. Int J Sci Study. 2014,1(6):9-13.

19. Dubashi SS, Wani R. Teenage pregnancy. Bombay Hosp J. 2008;50(2):236-9.

20. Mahavarkar SH, Madhu CK, Mule VD. A comparative study of teenage pregnancy. Am J Obstet Gynecol,2008;28(6):604-7.

21. Althabe F, Moore JL, Gibbons L, Berrueta M, Goudar SS, Chomba E, et al. Adverse maternal and perinatal outcomes in adolescent pregnancies: The Global Network's Maternal Newborn Health Registry study. Reproduct Health. 2015;12(2):S8.

22. Mukhopadhyay P, Chaudhuri RN, Paul B. Hospitalbased perinatal outcomes and complications in teenage pregnancy in India. J Health, Population, Nutrit. 2010;28(5):494.

23. Bacci S, Bartolucci F, Pieroni L. A causal analysis of mother's education on birth inequalities. arXiv preprint arXiv:12. 2012.

Cite this article as: Okram SD, Reddy KM,

Samyukta BSCN, Sadvika P, Betha K. Prevalence of teenage pregnancy and pregnancy outcome at a rural teaching hospital in India. Int J Reprod Contracept Obstet Gynecol 2019;8:613-6. 